\title{
LA DERROTA
}

DESPIERTA

LA CONCIENCIA

LA PRENSA DE LA

CIUDAD DE MÉXICO

ANTE EL TRATADO DE

GUADALUPE HIDALGO

EN 1848

Jesús Velasco*

E1 2 de febrero de 1848, se reunieron en la sacristía del Templo a la Virgen de Guadalupe los comisionados mexicanos Bernardo Couto, Luis Atristaín y Luis Gonzaga Cuevas con el de los Estados Unidos, Nicholas P. Trist, para firmar el Tratado de Límites, Comercio y Amistad entre México y Estados Unidos, por el cual se daba por terminada la Guerra que desde 1846 el gobierno estadounidense había declarado contra México. Ese tratado básicamente legitimaba las ambiciones de posesión territorial a costa del territorio mexicano que habían manifestado diversos gobiernos norteamericanos desde 1824, y que los de México habían resistido aun a costa de arriesgar una invasión como la que en esos años se había sufrido. Desde la declaración de guerra por parte de los Estados Unidos, la prensa mexicana denunció la agresión y la invasión que sufrió México. Con base en esto y en sólidos argumentos legales y morales

* Departamento Académico de Estudios Internacionales, ITAM. 
JESÚS VELASCO

mantuvo la posición de que México debía defenderse hasta agotar todos los recursos y negarse a firmar una paz oprobiosa, que además invitaría a más demandas injustas u otras intervenciones similares. Así pues, México se enfrentó desventajosamente a este reto. Pero después de la ocupación de la ciudad de México por el ejército al mando del general Winfield Scott, en septiembre de 1847, la virtual desaparición del ejército mexicano, y la crisis de la federación mexicana, ' los gobiernos de Manuel de la Peña y Peña y Pedro María Anaya no concibieron otra alternativa que negociar lo que antes había parecido imposible, y la prensa capitalina, en su mayoría, apoyó esa decisión. Con ello ayudó a crear un consenso a favor de algo a lo que antes se había opuesto. Sin embargo, este apoyo no es lo más rescatable de su empresa, sino las reflexiones en las que apoyó su argumentación; éstas hoy día, dadas las realidades nacionales, tienen un especial significado porque - guardadas las proporciones - nuestras condiciones actuales tienen cierta similitud con las que aquellos aciagos tiempos.

\section{La justificación del Tratado}

Como un eco de los partidos y los dirigentes políticos, la prensa de la ciudad de México se mantuvo intransigente a entrar en negociaciones con el comisionado norteamericano hasta que las tropas estadounidenses arribaron a las inmediaciones de la ciudad de México. Sin embargo, después de las derrotas de Padierna y Churubusco, al pactarse un armisticio, se manifestaron algunas opiniones a favor de llevar a cabo negociaciones. ${ }^{2}$ La ocupación de la ciudad de México, en sep-

${ }^{1}$ Véase Josefina Zoraida Vázquez (coordinación e introducción), México al tiempo de su guerra con Estados Unidos (1846-1848), 1997, México, FCE.

${ }^{2}$ Desde que el Congreso de los Estados Unidos declaró la guerra a México y el ejército norteamericano ocupó la margen septentrional del río Bravo, la prensa de la ciudad de México se mantuvo unánimemente inflexible a una negociación con Estados Unidos hasta que el 15 de mayo de 1847 apareció el diario El Razonador, el cual sostuvo la conveniencia de escuchar las 
LA DERROTA DESPIERTA LA CONCIENCIA

tiembre de 1847, obligó al gobierno federal a trasladarse a la ciudad de Querétaro y la prensa en la ciudad de México, se concretó a tratar los asuntos derivados de la ocupación y la contidianeidad de la vida citadina.

Mientras tanto el gobierno provisional se enfrentó a dos retos vitales: regularizar el funcionamiento del gobierno para darle legitimidad ${ }^{3}$ y dar solución al problema de la invasión; ambos se relacionaban, puesto que sin legitimidad no se podía enfrentar el dilema de mantener la resistencia o negociar, pero al mismo tiempo resolver este dilema podría atentar contra la legitimidad del gobierno. Sobre este último punto las opiniones estaban divididas, un grupo de estados, conformados en coalición, y dirigentes políticos se manifestaban a favor de continuar la resistencia armada, al tiempo que un grupo importante de miembros del partido "moderado" se manifestaban en favor de dar una solución negociada.

Mientras Manuel de la Peña y Peña, quien había asumido interinamente la presidencia, el 27 de septiembre de 1847, procedía a reorganizar el gobierno y obtener el apoyo de los gobernadores para iniciar conservaciones con Nicholas Trist, éste comunicó al ministro de Relaciones Luis de la Rosa, a mediados de octubre, su interés en reanudar las negociaciones de paz. Para entonces se habían llevado a cabo elecciones legislativas en 15 estados, ${ }^{4}$ con lo cual a principios de noviembre se reunió el Congreso, que nombró presidente provisional a Pedro María Anaya y le autorizó a reanudar las negociaciones que se habían llevado a cabo antes de ocupación de la ciudad de México. El 22 de

propuestas del recién nombrado comisionado Nicholas $P$. Trist. Posteriormente, después de la ocupación de la ciudad de México en septiembre de 1847 , la prensa liberal moderada se manifestó en favor de la negociación. Véase Jesús Velasco Márquez, La guerra del 47 y la opinión pública (18451848), 1975, México, SEP, p. 23-4.

${ }^{3}$ Vázquez, México al tiempo de su guerra..., op. cit., p. 43.

${ }^{4}$ Reynaldo Sordo Cedeño, "El Congreso y la Guerra con Estados Unidos de América, 1846-1848", en Vázquez, México al tiempo de su guerra..., op. cit., p. 97. 


\section{JESÚS VELASCO}

noviembre, De la Peña, quien ocupó la cartera de Relaciones Exteriores notificó al comisionado estadounidense la designación de los negociadores mexicanos, Bernardo Couto, Luis G. Cuevas y Miguel Atristaín. Pese a diversos problemas, entre ellos la revocación de la comisión de Trist, la negociaciones se reiniciaron el 2 de enero de 1848 y se continuaron durante un mes, con no menos problemas. Estas negociaciones se mantuvieron en el marco de una estricta confidencialidad y sólo dos días después de haberse firmado el tratado se dio la primera noticia en la prensa sobre el mismo. ${ }^{5}$

El tratado finalmente acordado contenía entre otros puntos la aceptación del río Bravo como límite meridional de Texas y la cesión de los territorios de Nuevo México y la Alta California, una indemnización de 15 millones de pesos y el reconocimiento de los derechos básicos de los ciudadanos mexicanos en esos territorios, ya fuera que decidieran reubicarse en México o permanecer en Estados Unidos. De hecho ante las condiciones desventajosas en que se encontraba México en aquel momento, la pérdida consignada en ese tratado había sido "forzosa e inevitable". 6

Aunque la explicación de los negociadores tenía un fuerte sustento legal y pragmático, los gobiernos de Anaya y Peña tuvieron que librar la batalla para crear un consenso nacional en favor de la ratificación del tratado, entre el 2 de febrero y el 21 de mayo de 1848. Tres corrientes dominaban la opinión pública articulada. La posición extrema en contra de la ratificación la asumieron un grupo de diputados y gobernadores "puros" encabezados por Valentín Gómez Farías y Manuel Crecencio Rejón; ellos se oponían a cualquier cesión territorial bajo el argumento de que el poder federal carecía de facultades para enajenar el territorio de los estados, y en consecuencia demanda-

${ }^{5}$ Daily American Star, 4 de febrero de 1848.

6 "Exposición dirigida al Supremo Gobierno por los Comisionados que firmaron el Tratado de Paz con los Estados Unidos", en Josefina Zoraida Vázquez, México y el Mundo, Historia de sus relaciones exteriores, 1990, México, Senado de la República, vol. I, p. 221. 


\section{LA DERROTA DESPIERTA LA CONCIENCIA}

ban la continuación de la resistencia armada. ${ }^{7}$ En un punto intermedio estaba la que había expuesto, desde septiembre de 1847, Mariano Otero, quien sostenía que la negociación se debía concretar al asunto de la anexión de Texas, sin aceptar la inclusión de otras cesiones territoriales y, si el gobierno estadounidense insistía en ellas, la guerra debía continuar; ${ }^{8}$ ésta era sostenida por un grupo de "moderados". Finalmente, estaba la del propio gobierno, consignada en el tratado y la cual recibía el apoyo de la mayoría de los moderados.

En estas condiciones, en la ciudad de México la prensa, dominada por los "moderados", se dio a la tarea de convencer a la opinión pública sobre la necesidad de que el tratado fuera ratificado en los términos negociados. Para ello se analizaron tanto las causas de la derrota mexicana, como la necesidad de aceptar las demandas norteamericanas, por injustas que éstas fueran.

El Observador Católico fue uno de los primeros diarios capitalinos que hizo una explicación global de las causas por las que México había sido derrotado. ${ }^{9}$ Según éste, la justicia había estado en todo

7 “Exposición o Programa de los diputados pertenecientes al partido puro o progresista sobre la presente guerra, con motivo de una proposición del señor Otero, e imputaciones de ciertos periódicos que se publican en la capital, bajo la influencia del conquistador, y que se dejan correr libremente por el actual gobierno de la Unión", en Lillian Briseño Senosiáin, et al., Valentín Gómez Farias y su lucha por el Federalismo, 1822-1858, 1991, México, Instituto Mora, p. 389; Manuel Crecencio Rejón, Observaciones del diputado saliente Manuel Crecencio Rejón contra los tratados de paz, firmados en la ciudad de Guadalupe el 2 del próximo pasado febrero, precedidos de una parte histórica relativa a la cuestión originaria, 1848, Querétaro, Imprenta de J. M. Lara.

${ }^{8}$ Mariano Otero, "Comunicación que sobre las negociaciones diplomáticas habidas en la Casa de Alfaro, entre los plenipotenciarios de los Estados Unidos y México, dirigió al Excmo. Sr. Gobernador de Jalisco, en Jesús Reyes Heroles (recopilación, selección, comentarios y estudio preliminar), Mariano Otero, Obras, 1967, México, Porrúa, p. 537-56.

9 "Tratado de Paz", El Observador Católico, 29 de abril de 1848, p. 142. 


\section{JESÚS VELASCO}

momento de parte de México. El fracaso no se había producido únicamente por la inferioridad "del valor de nuestros soldados" ni por el atraso en conocimientos militares; tampoco había sido el producto de la traición ni de la miseria pública. Había una causa mucho mas profunda: "los errores políticos". La humillación y el abatimiento de México en 1848 eran la cosecha de las "innobles y vergonzosas luchas civiles".

Éstas despoblaron nuestras ciudades, atrasaron entre nosotros las ciencias y las artes, arruinaron nuestro comercio, aumentaron la miseria pública, desmoralizaron al pueblo, provocaron con el desengaño el egoísmo general, y produjeron por último resultado, esa indiferencia en todas las clases de la sociedad, esa indiferencia funesta, síntoma inequívoco de la muerte de las naciones.

Tales luchas, además, habían vaciado los arsenales, agotado física y moralmente todos los recursos de la nación. Habían dejado inerme a México en manos "del extranjero audaz" que había querido invadirlo. El resultado, por lo tanto, no había sido otro que el natural, el lógico.

El Monitor Republicano hacía una especie de acto de contrición y sostenía que la guerra se había anunciado "con bastante anticipación", y que los mexicanos la debían haber evitado oportunamente. Los norteamericanos habían pecado de ambición, y los mexicanos "de orgullo". Estos últimos se habían dejado llevar por una sobrevaloración de sí mismos y un desprecio del enemigo. ${ }^{10}$ El Eco del Comercio pensaba que México había ofrecido "al mundo" el espectáculo de su "debilidad e impotencia". Aquello que se había esperado que la guerra produjese: unión entre los mexicanos, desprendimiento de las clases pudientes, respeto a las autoridades del país, disciplina en el ejército, no habían sido más que puras y simples quimeras. Los antecedentes mismos de México claramente habían mostrado que nada de eso se produciría frente a un enemigo como los Estados Unidos. ${ }^{11}$

10 "Frutos de la Guerra", El Monitor Republicano, 7 de julio de 1848, p. 3.

11 "Cuestiones Sociales", El Eco del Comercio, 16 de marzo de 1848, p. 4. 
La culpabilidad de la derrota recaía sobre los antecedentes mismos de la historia de México, pero también sobre todos aquellos, en especial gobernantes y periodistas, que pese a conocer esa historia habian exigido el inicio y la prosecución de la guerra. ${ }^{12} \mathrm{El}$ único gobierno exonerado de culpabilidad era el del general José Joaquín Herrera. Él y los miembros de su gabinete habían sido los únicos que no sólo se habían dado cuenta de la situación en que se encontraban México y los Estados Unidos, sino que se habían opuesto responsablemente a la guerra. Aquellos hombres jamás habían esperado que el éxito fuera favorable a México y asi lo habían dejado saber a toda la nación. Pero el pueblo y la prensa se habían burlado de "sus predicciones" y los habían "apellidado de traidores". 13

El ministerio del 6 de diciembre, que vio la cuestión de la guerra de Tejas con bastante tacto y previsión, y que habló francamente a la república, se le llamó traidor e infame... Los que le han sucedido hasta la fecha, han tenido por lema de sus procedimientos la guerra, y no han hecho ni el arreglo honroso que pudo haber concluido la administración del 6 de diciembre, ni una sola operación militar que redunde en provecho y en honra de esta nación... ${ }^{14}$

La "Cuestión de Tejas", se volvió a mencionar. Si los mexicanos hubieran reconocido su independencia o su anexión, que de hecho existían en el momento de su legalización por los norteamericanos, México no hubiera tenido que soportar la guerra, hubiera recibido una mejor indemnización por el territorio entre el Nueces y el Bravo, y no hubiera perdido Nuevo México y California. Más aún, si desde el momento mismo en que Texas se había declarado independiente México la hubiera reconocido, habría sido de infinita utilidad

12 "Conclusión definitiva para la paz", ibid, 4 de mayo de 1848, p. 3.

13 "Temores de una nueva revolución", El Siglo XIX, 2 de junio de 1848, p. 4. ${ }^{14}$ El Eco de Comercio, 4 de mayo de 1848, p. 3. 
JESÚS VELASCO

...bien por formarnos en ella una república hermana y amiga, en lugar de una hija rebelde, bien por ahorrar el mucho gasto que nos traería tenerla siempre quieta, sofocando continuamente sus conatos de separación, bien por los millones que podría proporcionarnos el reconocimiento de su independencia, su cesión o venta, o, finalmente, porque podría servirnos de una barrera entre nosotros y los Estados Unidos. ${ }^{15}$

Con respecto al tratado mismo los diarios capitalinos tomaron como punto de partida la Exposición hecha por los comisionados, en algunas ocasiones ampliando los conceptos ahí vertidos y otras simplemente repitiendo aun el texto mismo. El Observador Católico, desde el 29 de abril, presentó el tratado de paz o la continuación de la guerra como "la gran cuestión", de la cual dependía "nuestra nacionalidad, nuestra religión, nuestra existencia misma". Para demostrar la necesidad que México tenía de aceptar la paz, afirmó que no se contaba con un ejército, ni material bélico, ni recursos económicos con qué procurárselo. Los pocos soldados con los que se contaba estaban desmoralizados; "desconfiando de sus jefes" y se rehusaban a batirse de nuevo.

84 El enemigo, en cambio, tenía "un ejército acostumbrado a la victoria, triplicadas sus fuerzas, con un material inmenso, con recursos de todas clases" y que se hallaba en posesión de los mejores puntos de la república: ${ }^{16} \mathrm{Y}$ después de relatar de esta manera el contraste militar de ambós contendientes, el diario preguntaba: "¿podríamos continuar la guerra con probabilidades de éxito?" La respuesta era obvia, la continuación traería consigo males "sin cuento y hasta el exterminio de nuestra raza". Se pedía al Congreso Mexicano aceptar el tratado de paz, a pesar de "la injusticia de las condiciones", y concluía afirmando:

México tendrá un poco menos de extensión, es cierto, pero si salva su nacionalidad e independencia, quédanle todavía abun-

${ }^{15}$ El Monitor Republicano, 7 de julio de 1848 , p. 3.

${ }^{16}$ El Observador Católico, 29 de abril de 1848, p. 142. 


\section{LA DERROTA DESPIERTA LA CONCIENCIA}

dantísimos recursos para llegar a formar una de las primeras naciones del mundo.

El Eco del Comercio, en su editorial de 9 de mayo, ${ }^{17}$ se expresó de manera similar. "La imperiosa ley de la necesidad" obligaba a los mexicanos a aceptar la firma de un tratado de paz como principio de conservación. México carecía de los recursos morales y materiales para continuar la lucha, y pretender esto sería "la continuación de nuestra ignominia". México tenía que hacer el sacrificio de su "pundonor nacional" al aceptar el derecho del más fuerte y la pérdida de una parte de su territorio, "muy considerable ciertamente, pero a la cual no llegaban nuestros brazos" y cuyas riquezas no podíamos explotar. El sacrificio de su amor propio era el único recurso que le quedaba al país para conservar "su independencia, nacionalidad y ser". Por otra parte, la pérdida del territorio no sería total, ya que por él se recibiría "una indemnización más o menos equivalente".

El Siglo XIX, en su editorial de 2 de junio, ${ }^{18}$ después de efectuado el canje de instrumentos, se dio a la tarea de defender el tratado y a sus negociadores. Afirmaba que si bien era cierto que las pretensiones de los Estados Unidos habían sido injustas, ante los resultados de la guerra México no podía hacer otra cosa que aceptarlas. Se consideraba "conveniente para salvar a la nación" ceder una parte de ella. Para ejemplificar se planteaba la siguiente pregunta: ¿No viola uno. de los primeros preceptos de la naturaleza el hombre que para salvar su vida se negara a sufrir la amputación de un miembro?

Ahora bien, la preocupación por la población de los territorios cedidos se calmaba pensando que para ellos era mejor quedar integrados a los Estados Unidos que padecer los estragos de la prolongación de la guerra. En cuanto a que el gobierno no tuviera autoridad para ceder territorios de la nación, se contestó que no era el gobiemo quien los cedía, sino "la nación misma que amenazada de una ruina total y casi

17 "La Paz en las actuales circunstancias", El Eco del Comercio, 9 de mayo de 1848 , p. 4.

${ }^{18}$ El Siglo XIX, 2 de junio de 1848, p. 4. 


\section{JESÚS VELASCO}

cierta", cedía una parte de lo suyo para conservar el resto. A la última cuestión, o el peligro de la proximidad con los Estados Unidos, se respondió que el Tratado no abría este peligro, pues éste había existido aún antes de que la guerra hubiera comenzado. Los Estados Unidos, por otra parte, se habían convertido en peligro, porque los mexicanos mismos habían debilitado a su país.

...lo que hoy hemos perdido no nos lo quita el Tratado, nos lo arrebata nuestra locura, y ésta y no aquél, será (y Dios no lo permita) la que nos borre del catálogo de las naciones.

En suma, el Tratado de Guadalupe Hidalgo no era necesario sino indispensable. Nadie era culpable en particular, sino toda la nación mexicana.

Un argumento importante por el que la mayor parte de los diarios de la ciudad de México recomendó la inmediata aceptación del tratado de paz, fue el temor a la anexión total de México a los Estados Unidos. Desde mayo de 1847 se había iniciado en Estados Unidos un movimiento periodístico que pedía la anexión total del territorio mexicano a la Unión Americana. Para principios de 1848 esta opinión se había apoderado de los debates del Congreso norteamericano. ${ }^{19}$ Mientras tanto, en la ciudad de México después de la ocupación los norteamericanos empezaron a exponer estas ideas expansionistas a través de dos periódicos, The American Star y The Northamerican. A fines de 1847 el escándalo de las elecciones para el Ayuntamiento de la ciudad de México, ${ }^{20}$ que

${ }^{19}$ Lambert, Paul, "The All-México Movement", en Odie B. Faulk y Joseph A. Stout, Jr. (eds.), The Mexican War Changing Intrepretations, 1973, Chicago, The Swallow Press, p.165; Josefina Vázquez de Knauth, "El Congreso de los Estados Unidos y la guerra del 47", Anglia. Anuario de Estudios Angloamericanos, 1973, México, UNAM, n 5, p. 71.

${ }^{20}$ José María Roa Bárcena, Recuerdos de la invasión norteamericana (1846-1848), 1947, México, Porrúa, t. III, p. 205-12; Alejandro Villaseñor y Villaseñor, Antón Lizardo. El Tratado MacLane-Ocampo. El Brindis del Desierto, 1962, México, Jus, p. 291-6. 
terminó con el resonado caso de "El Brindis del Desierto", ${ }^{21}$ confirmó las sospechas de que entre los mismos mexicanos existía una fuerte tendencia anexionista. Y más aún, desde que se empezaron a divulgar las noticias de que el gobierno de Querétaro estaba en pláticas con el representante norteamericano, Nicholas Trist, los levantamientos en contra de que se firmara un tratado de paz no se hicieron esperar. El 12 de enero en San Luis Potosí se había lanzado un plan desconociendo al gobierno de Querétaro. El 16 del mismo, en Guanajuato amenazó con reasumir su soberanía. El mismo día lo hizo la guarnición de Guadalajara. Por su parte, y por sus peculiares problemas, Yucatán ofreció el 25 de marzo el dominio y soberanía de su territorio a los Estados Unidos, ${ }^{22}$ lo cual sería el objeto de un mensaje enviado por el presidente Polk al Congreso el 29 de abril. ${ }^{23}$ Ese mismo día, El Observador Católico, comentaba que existían rumores de que algunos diputados mexicanos "iban a oponerse resueltamente al tratado, para lograr por ese medio la entera conquista del país y la agregación a los Estados Unidos". ${ }^{24}$ Finalmente, un día después del canje de instrumentos el sacerdote y guerrillero, Celedonio Jarauta, junto con Martínez Negrete, lanzaron un plan desconociendo a ambos, el gobierno de Querétaro y el Tratado de Guadalupe Hidalgo, a este plan se unirían más tarde Manuel Doblado y Mariano Paredes. ${ }^{25} \mathrm{Y}$ para completar el cuadro de confusión, se empezaron a publicar constantemente noticias sobre la proyectada República de Sierra Madre y la participación en el asunto de filibusteros norteamericanos. ${ }^{26}$

${ }^{21}$ Enrique Olavarría y Ferrari, México a través de los siglos, 1958, México, Cumbre, t. IV, p.709; José María Roa Bárcena, op. cit., t. III, p. 215.

${ }^{22}$ José María Roa Bárcena, op. cit., t. III, p. 251 y 301-2.

${ }^{23}$ José C. Valadés, Orígenes de la república mexicana. La aurora consfitucional, 1972, México, Editores Mexicanos Unidos, p. 568.

${ }^{24}$ El Observador Católico, 19 de abril de 1848, p. 142.

${ }^{25}$ El Siglo XIX, 15 de junio de 1848, p.1; Olavarría y Ferrari, op. cit., p.712; Calendario de Galván, 1851, p. 56.

26 "Más sobre la República de Sierra Madre", El Siglo XIX, 3 de octubre de 1848 , p. 3. 
JESÚS VELASCO

La prensa capitalina pensó que todos estos movimientos no eran otra cosa que el producto de facciones políticas, cuyas opiniones eran "diametralmente opuestas", pero que buscaban el aniquilamiento de la independencia de México. Una perseguía el establecimiento de la monarquía bajo la protección de Europa; la otra, llevaba "las ideas democráticas a un extremo pernicioso". ${ }^{27}$ Pero cualquiera de las dos implicaba la enorme posibilidad de que México fuera anexado en su totalidad a los Estados Unidos. ${ }^{28}$ Por ello, los periodistas mexicanos sostuvieron que la paz y la restauración de relaciones con los Estados Unidos eran necesarias, puesto que éstos eran los únicos medios para exigir al gobierno norteamericano que mantuviera a sus habitantes al margen de los problemas internos del país. Por otra parte, también se dieron a la tarea de mostrar las inconveniencias de la incorporación total de México a la Unión Americana.

El Observador Católico hizo notar que los beneficios materiales que los norteamericanos habían prometido a los habitantes de Nuevo México, por ejemplo, no se habían cumplido. Por el contrario, se habían cometido "horribles crueldades", especialmente con los mexicanos rebeldes en $1846 .{ }^{29}$ EI Siglo XIX comentaba la situación del territorio que México había cedido y el comportamiento de los norteamericanos como sigue:

Nos escriben del Paso del Norte dándonos la noticia de que en Nuevo México crece cada día más el desconcierto que produjo la noticia de la cesión de aquel territorio a los Estados Unidos: y que lo que más disgusta a aquellos pueblos es la frecuencia

${ }^{27}$ El Eco del Comercio, 9 de mayo de 1848, p. 4.

${ }^{28}$ Desde el año de 1846 el asunto de la anexión de México a los Estados Unidos había sido discutido por la prensa mexicana. El Tiempo había acusado entonces a los diarios liberales de querer anexar todo el territorio mexicano a aquella nación. Éstos, a su vez, se defendieron achacando a El Tiempo de ser él el que atentaba contra la soberanía e independencia de México.

29 "Colonización. Tolerancia de Cultos", El Observador Católico, 16 de septiembre de 1848 , p. 622. 
con que están teniendo que hacer desembolsos de dinero a que no estaban acostumbrados. Se asegura también, que no pueden acomodarse a las costumbres de los norteamericanos. Las tropas de éstos, en su retirada, han cometido excesos de todo género. En su tránsito por El Paso han matado a algunos mexicanos y herido a otros, sin que se sepa el motivo; han talado las sementeras con sus caballerías; han arruinado las viñas, y cuando se les ha reconvenido o han contestado que no entienden lo que se les dice o han amenazado con las armas. Son en verdad insufribles, la audacia y la barbarie de los soldados de una nación que se llama civilizada. Damos estos avisos a los candorosos anexionistas. ${ }^{30}$

En otro nivel, El Eco del Comercio comentó que la anexión de México a los Estados Unidos sería desventajosa para los mexicanos pues, los americanos buscaban "el dominio de su raza" y por ello, en el momento en que una población de diferente tronco racial cayera en el ámbito de su autoridad, se encontraría en nivel de inferioridad. Este diario hizo especial hincapié en la idea de que al llevarse a cabo la anexión se iniciaría el proceso de "destrucción y abatimiento de la raza indígena"

...y a falta de ésta, la anglosajona comenzaría a predominar, llegando dentro de muy poco tiempo a quedar reducida a la más completa nulidad la hispanoamericana. ${ }^{31}$

El Siglo XIX recogió estas ideas en su editorial titulado "Anexación" del 29 de octubre de 1848 y profundizó más en el problema. Si los mexicanos llegaban a someterse al gobierno y autoridad de los Estados Unidos, pronto se llegaría a una situación similar a la de la época colonial.

30 "Nuevo México", El Siglo XIX, 27 de octubre de 1848, p. 4.

31 "Estados Fronterizos", El Eco del Comercio, 28 de junio de 1848, p. 4. 


\section{JESÚS VELASCO}

Las leyes que nos regirán contendrían, no lo dudamos, para nosotros las fórmulas de los derechos de los hombres libres; pero su autoridad no bastaría para confundir en uno solo caracteres tan opuestos, como el de la raza anglosajona y la mexicana. Por más que el nuevo gobierno fuese equitativo, no podría evitar que los hijos de la primera ejerciesen, sobre los de la segunda, la superioridad que da la fuerza y que da la ilustración; menos evitaría que los segundos convencidos de su debilidad, reputasen como un yugo insoportable la tolerancia respecto de unas costumbres tan extrañas a sus hábitos... ¿Qué podemos esperar de los Estados Unidos? Díganlo nuestros hermanos del Nuevo México y la California, cuya suerte y derechos, el Congreso de aquel pueblo ni aun se ha dignado discutir, dejándolos sometidos al despotismo militar. ${ }^{32}$

Y concluía diciendo, que si el pretexto para inclinarse a ser anexados a la Unión Americana era la efectividad de sus instituciones, los mexicanos debían hacer "como los romanos, que copiaron las leyes de los atenienses, sin pedirles su gobierno, ni someterse a su dominación". Además, lo que a México le faltaba no eran leyes, ni tampoco instituciones, sino responsabilidad cívica y educación para entender sus leyes.

Curiosamente los argumentos sobre los que la prensa de la ciudad de México justificó la necesidad de firmar un tratado de paz y mantener ésta con los Estados Unidos, fueron exactamente los mismos sobre los que apoyó anteriormente su furor bélico. La paz era necesaria para detener el expansionismo norteamericano, para lograr el respeto internacional, para que el espíritu de nacionalidad no se acabara de perder, para iniciar la reestructuración interna de la sociedad y las instituciones, y finalmente, para preservar la raza y la cultura hispánicas.

32 “Anexación” [sic], El Siglo XIX, 29 de octubre de 1848, p. 3. 


\section{Significado de la guerra y la derrota}

La ratificación del Tratado de Guadalupe Hidalgo, el 30 de mayo de 1848, hasta cierto punto calmó la ansiedad pública de la ciudad de México, aunque fue considerado "el hijo de veinte y cinco años de desarreglos y de infortunios", el fruto de la debilidad de México y de "los muchos vicios de su sociedad". Había sido dictado por la necesidad, y por tanto no era nada "lisonjero". No obstante, México había logrado conservar algo, "pudiendo haber perdido todo". Esta última posibilidad llevó a los mexicanos a hacer un examen del significado de la derrota sufrida. Era el momento de hacer un análisis de la trayectoria de México desde su independencia, para que en adelante no se cometieran las mismas faltas. ${ }^{33}$

El Eco del Comercio, resumiendo la opinión de todos los diarios de ese año, afirmó que México, como un ser vivo que era, se había separado de "la casa paterna", y "embriagado con la gloria que había adquirido luchando sin auxilio en la sangrienta guerra de su independencia", había exagerado su amor propio, haciéndose vano y presuntuoso. Las ideas de libertad "que brillaban en un pueblo vecino" lo habían deslumbrado, y por ello México había pretendido hacer "una violenta transición desde el simple estado de colonia hasta la más ilimitada libertad". Cual jóvenes "licenciosos e incautos", los mexicanos se habían lanzado por una senda de excesos, que los había llevado a la encrucijada de la ruina o la rectificación. ${ }^{34}$ Tal era el significado de la derrota. O como decía El Monitor Republicano:

Ahora lo que conviene es aprovecharnos de lo sucedido... Éste es el único fruto que puede sacar a la república de nuestras desgracias pasadas... Mucho hemos ganado... No faltará quién se escandalice con esta proposición... ${ }^{35}$

33 "La Paz", El Eco del Comercio, 22 de mayo de 1848, p. 4.

34 “Reorganización", ibid, 25 de mayo de 1848 , p. 3.

${ }^{35}$ El Monitor Republicano, 7 de julio de 1848, p. 3. 
JESÚS VELASCO

Los periódicos mexicanos, como se puede ver, aceptaron que la guerra le daba a México la esperanza de un porvenir mejor. Esta esperanza se basaba en la dura lección recibida. En efecto, la desastrosa guerra de que había sido teatro la república, con tanta fortuna para el enemigo, y tanta desgracia para los mexicanos, purificó en cierto modo las opiniones y las ideas. El riesgo que corrió México de desaparecer para siempre como nación independiente hizo que sus habitantes sintieran vivamente los efectos de sus desaciertos y desearan realmente un cambio. "Los Frutos de la Guerra" fueron que ésta

...[hubiera] puesto a la nación en un estado capaz de recibir cualquier reforma que nunca habría logrado permaneciendo como estaba y mucho menos si la suerte de las armas nos hubiera sido favorable. Ciertamente parece una paradoja, que si atendemos a la sustancia de las cosas y quitamos la vista de apariencias deslumbradoras, puede ser que haya sido más útil para la República la derrota que la victoria. ${ }^{37}$

La guerra parecía haber demostrado en algunas ocasiones que los 92 mexicanos eran capaces de unirse en torno a un ideal común. Acontecimientos "como los del Peñón Viejo", decía El Monitor Republicano, habían sido tan formativos, que "si para volver a gozar días semejantes" era una necesidad que el enemigo estuviera a la vista, "multitud de mexicanos lo desearían así". ${ }^{38}$ La guerra había demostrado, también, los efectos de la desunión. ${ }^{39}$ Los Estados Unidos estaban al acecho de los errores de México para aprovecharlos en sus afanes expansionistas. ${ }^{40}$ Y la guerra había acabado también con el prestigio de la casta militar

36 "Revista Política de México", El Eco del Comercio, 11 de julio de 1848, p. 3.

${ }^{37}$ El Monitor Republicano, 7 de julio de 1848, p. 3.

38 "Acontecimientos Frescos", ibid, 14 de agosto de 1848, p. 3.

${ }^{39}$ El Siglo XIX, 2 de junio de 1848, p. 4.

40 "La Paz", El Monitor Republicano, 3 de junio de 1848, p. 3. 
y había mostrado el egoísmo de otros grupos sociales. En fin, para México se abría en ese momento

...una era más interesante y difícil que la que comenzó con la independencia... si hoy la nación no se hace fuerte por el orden y civilización, desaparecerá antes de muchos años nuestra nacionalidad, de manera que exterminada nuestra raza, perdidas nuestras costumbres, y nuestras tradiciones y olvidado hasta nuestro idioma y nuestros nombres, dejaremos sobre la tierra de nuestros padres, un vestigio más débil que el que ha quedado de nuestros primitivos y valerosos pobladores... ${ }^{41}$

A partir de ese momento México podía empezar a desarrollarse, pero sólo podía hacerlo en base a las experiencias de la guerra; de otra manera la paz podría serle aún más perjudicial de lo que la guerra había sido. De aquí que los periódicos se preguntaran:

...si al terminarse nuestro arreglo con los Estados Unidos habremos conseguido solamente haber perdido una inmensa extensión del territorio quedando como siempre con nuestras antiguas revoluciones de cada seis meses, nuestra empleomanía y nuestra absoluta falta de juicio para gobernarnos. ${ }^{42}$

La esperanza de este momento era que la firma del Tratado de Guadalupe Hidalgo, abriría una era en que en México empezaría a reinar la calma social; ${ }^{43}$ en que las experiencias sufridas se traducirían en programas de educación para el pueblo, "poniéndolo al nivel de las instituciones", dándole goces que le hicieran amar a su gobierno y despertar "ese sentimiento natural que hace a los hombres amar a la patria". 44

41 "Introducción", El Siglo XIX, 1 de junio de 1848, p. 1.

42 "Cuestiones Sociales", El Eco del Comercio, 13 de marzo de 1848, p. 3. ${ }^{43}$ El Eco de Comercio, 22 de mayo de 1848, p. 4.

44 "El Pasado y el Porvenir", El Siglo XIX, 19 de noviembre de 1848, p. 3. 


\section{JESÚS VELASCO}

México podría algún día "lavar de un modo glorioso la mancha con que había empañado su honor la guerra pasada. ${ }^{45}$ En el ambiente general se sentía la necesidad de una reforma, ya fuera conservadora ${ }^{46} \mathrm{o}$ liberal. ${ }^{47}$ Lo importante era basarla en el reconocimiento del "interés común" para que lograra hacer feliz a la nación. ${ }^{48}$ Era importante que "teniendo a la vista el ejemplo vivo y palpitante de lo pasado", los mexicanos adoptaran una marcha enteramente nueva y "opuesta a la marcha antigua". Que los partidos deponiendo sus viejos rencores "en aras de la patria", se lanzaran por la vía de la legalidad e hicieran de México lo que México debía ser. ${ }^{49}$

En las consideraciones finales de la Exposición de los comisionados mexicanos éstos afirmaron:

Pliegue al Todopoderoso que la dura lección que acabamos de pasar, sirva para hacernos entrar en buen consejo, y curarnos de antiguos vicios. Sin esto nuestra perdición es segura: por el camino que hemos seguido, se llegará siempre al punto donde estábamos... y no siempre será dado salir de él. México acabará y acabará... con ignominia. ${ }^{50}$

Después de 150 años de haber sido firmado un tratado por demás lacerante, cabría recordar estas considraciones y preguntarnos si no serían válidas para nuestra realidad nacional hoy día.

${ }^{45}$ El Observador Católico, 29 de abril de 1848, p. 142.

${ }^{46}$ Ibid., 16 de septiembre de 1848, p. 622.

47 "El Partido Dominante", El Siglo XIX, 17 de septiembre de 1848, p. 3; "El Partido Puro", ibid, 28 de septiembre de 1848, p.3; "Moderados", ibid, 29 de septiembre de 1848 , p. 3.

${ }^{48}$ El Monitor Republicano, 3 de junio de 1848, p. 3.

${ }^{49}$ El Eco del Comercio, 22 de mayo de 1848, p. 4.

50 "Exposición de los comisionados..., Vázquez, México y el Mundo..., op. cit., p. 244. 


\section{LA DERROTA DESPIERTA LA CONCIENCIA}

\section{Fuentes y bibliografía}

Hemerografia

Daily American Star, 1847

El Eco del Comercio, 1848

El Monitor Republicano, 1848

El Observador Católico, 1848

El Razonador, 1847

El Siglo XIX, 1848

Calendario de Galván, 1851

\section{Fuentes secundarias}

Briseño Senosiáin, Lillian, et al., Valentín Gómez Farias y su lucha por el Federalismo, 1822-1858, 1991, México, Instituto Mora.

Faulk, Odie B. y Joseph A. Stout, Jr. (eds.), The Mexican War Changing Interpretations, 1973, Chicago, The Swallow Press.

Olavarría y Ferrari, Enrique, México a través de los siglos, 1958, México, Cumbre.

Rejón, Manuel Crecencio, Observaciones del diputado saliente Manuel Crecencio Rejón contra los tratados de paz, firmados en la ciudad de Guadalupe el 2 del próximo pasado febrero, precedidos de una parte histórica relativa a la cuestión originaria, 1848, Querétaro, Imprenta de J.M. Lara.

Reyes Heroles, Jesús (recopilación, selección, comentarios y estudio preliminar), Mariano Otero, Obras, 1967, México, Porrúa.

Roa Bárcena, José María, Recuerdos de la invasión norteamericana (18461848), 1947, México, Porrúa.

Valadés, José C., Orígenes de la república mexicana. La aurora constitucional, 1972, México, Editores Mexicanos Unidos.

Vázquez, Josefina Zoraida (coordinación e introducción), México al tiempo de su guerra con Estados Unidos (1846-1848), 1997, México, FCE. 


\section{JESÚS VELASCO}

Vázquez, Josefina Zoraida, México y el Mundo, Historia de sus relaciones exteriores, 1990, México, Senado de la República, v. I.

Vázquez de Knauth, Josefina, "El Congreso de los Estados Unidos y la guerra del 47", Anglia. Anuario de Estudios Angloamericanos, 1973, México, UNAM, $\mathrm{n}^{\circ} 5$.

Velasco Márquez, Jesús, La guerra del 47 y la opinión pública (18451848), 1975, México, SEP.

Villaseñor y Villaseñor, Alejandro, Antón Lizardo. El Tratado MacLaneOcampo. El Brindis del Desierto, 1962, México, Jus. 